\title{
Research on the Economic Benefits of Immigration in Canada
}

\author{
Shenghan Sun \\ ${ }^{1}$ The Westside School, Vancouver, British Columbia, V6B 1A9, Canada. \\ *Corresponding author. Email:info@thewestsideschools.ca
}

\begin{abstract}
In the last three years, it is found that many Canadian citizens regard that there are too many immigrants living in Canada. As a result, whether the Canadian government should continue to conduct a positive immigration policy has also been under discussion for a long time. This paper aims to figure out whether positive immigration policy should still be conducted in the future according to present economic contribution that Canadian immigrants have accomplished. In this paper, Canadian immigration and economy act as the main objects of the study. Data analysis is widely used, providing direct evidence to illustrate the features of the two objects, such as the age percentage of the immigration and the most contributive field of economy. At the same time, several related theories are used with the purpose of representing the logical relationship between the two objects. Research and works of literature are the major tools throughout the paper, and most of data come from them. All the resources can be found on the Internet. Based on all the analysis and inference, it turns out that the Canadian immigration plays a vital role in accelerating the development of the national economy. Therefore, the conclusion is that the Canadian government should continue to conduct immigrant-friendly policies.
\end{abstract}

Keywords: Canada; Immigration, Aging population, Knowledge economy

\section{INTRODUCTION}

The controversy surrounding the reasonableness of positive immigration policy is aroused because of the pessimistic public attitude towards increased immigration to Canada. Immigration, defined as the action of coming to live in a foreign country permanently, is becoming a more and more popular trend sweeping the world in this era of globalization. For Canada, especially, "the movement of individuals of one country into another for the purpose of resettlement is central to Canadian country," as The Canadian Encyclopedia mentioned[1], since the history of the first group of immigrants can date back to as early as the 17th century, and immigrants have accelerated and devoted to the development of many fields, such as economy, health and social services, security and settlement: half of all science, technology, engineering and mathematics (STEM) degree holders in Canada are immigrants, and they use these skills that are vital to the knowledge economy to make an incredible profit; according to the 2016 Census, more than 335,000 immigrants work in health-related occupations; in a ten- year period (1997-2017), the number of economic migrants living outside Ontario, British Columbia and Quebec increased by 10 percent (based on data from the official website the Canadian Government[2]). Immigration to Canada should be increased because of the benefits that this brings to Canada's economy. This paper particularly targets the benefits the Canadian immigration brings to the Canadian economy, varying from releasing the burden of social service as the aging population is growing in the country to accelerating the development of national knowledge economy to consider the Canadian economy's competitive place in the world. Data is widely and carefully collected and analyzed in this paper, aiming to explain the features of the Canadian immigration and economy. Several theories are referred to illustrate the relationship between the increased immigration to Canada and the country's economic development, the reason the immigration can make such a contribution, and so on. This paper points out the necessity of increasing the number of immigrants to Canada. It provides evidence for the government to continue its immigrant-friendly policy reasonably. 


\section{THE POSITIVE INFLUENCE OF INFLUX OF WORK-AGE IMMIGRANTS ON OFFSETTING THE PROBLEM OF ITS AGING POPULATION}

\subsection{The Current Situation of the Aging Population in Canada}

The increase of the aging population in Canada is unignorable, with the consideration of a series of social problems it might bring to the whole society. Such a negative situation has already taken place in Canada. According to ranks provided by PRB, in 2019, Canada became the country with the 22th largest percentage of older adults in the world range, with $17 \%$ of the total population regarded as the senior population[3]. Furthermore, there is a tendency for the aging population to grow faster in the country, and it seems that the problem of the aging population is not going to be solved properly in the short term. As Financial Post reported, Canadian society is tending to be a more aging one since life expectancy is expected to increase. By 2040, a quarter of the Canadian population will be in the age group of $65+, 17$ percent more than today[4]. Undoubtedly, an increasingly aging population represents greater pressure on society. In the paper Problems of an Aging Population in an Era of Technology, the author demonstrates the challenges Canadian health care services are facing because of an increasingly aging population: many acute medical facilities are used by the elderly, and some hospitals have no choice but to separate a new department to treat senior patients. "Increasing and upgrading the standards of chronic facilities for the elderly is also a challenge," the author mentions[5]. It is unlikely to be fair for medical institutions to treat a particular group of people in society with a large proportion of limited medical resources, and this might even lead to a deeper social controversy between various groups of people. Taking social support programs as a detailed example as well, the social support program actually resembles intergenerational transfers from workers to the retired elderly or to very young dependents. It is just like the beam with two extremes of workers and beneficiaries: now with a more senior population, the beneficiary side is becoming heavier and heavier which is leading to unbalance of the whole social welfare system. The only two ways to balance this beam again is either put more weights on the worker side or remove some of them from the beneficiary side, just like Financial Post said, "The impact of having fewer Canada Pension Plan contributions from workers and more payments going out to beneficiaries is also straightforward: Either workers contribute more or beneficiaries get paid less". For a welfare state like Canada, it is unlikely that the government would choose to decrease the payments for beneficiaries, but instead to increase the contribution from workers, which is a part of social savings. According to the life-cycle theory first proposed by Samuelson (1975)[6], a society with relatively more young workers will experience a higher level of social savings. Therefore, having more young workers in society can buffer the stress from Canada Pension Plan.

\subsection{The Vital Role New Immigrants Play in Easing the Burden of the Aging Society}

For the stress from Canada Pension Plan, if the Canadian Government wants to relieve this burden relatively quickly and effectively, it is not a wise choice to wait for the Canadian teenagers to grow up to work age, besides, Canada's fertility level has been descending continuously for the last 10 years, according to Statista. To counteract this, immigration could be the answer. According to Statista, in 2020, $75.35 \%$ of immigrants were of working age (age between 1564)[7].This is a more reasonable choice because immigrants can help relieve the burden from the Canada Pension Plan effectively in a relatively short time. In addition, they have the potential to optimize the aging makeup of the Canadian population. Meanwhile, Canada can make more profit that is big enough to cover the cost for immigrants since most of them can feed themselves and pay taxes as the capital of Canada Pension Plan. Second, the arrival of immigrants (as the paper mentioned before, over half of them are of working age) can fill the labour market again, especially when local citizens become older and retire and the birth rate is relatively low. The increasing number of immigrants represents the stronger labour force of the country. In addition, immigrants also devote themselves to health and social services. According to IRCC, based on the 2016 census, over 33,500 immigrants take healthrelated jobs as their life careers. Such a contribution of immigrants releases the pressure on the Canadian medical system, providing proper or even better medical services to the aging group. All in all, the influx of young immigrant workers can offset the problem of its aging population and even make more profit to the country. The economic benefits that immigrants make are also proved by the Canadian Government, as it predicts that "starting in 2031 , more than $80 \%$ of its growth is projected to come from immigration, compared to about $67 \%$ in 2011 [8]," which means that immigrants play the main character in the economic development in Canada. It is reasonable to accept immigrants moving to the country. At the same time, the fields that many immigrants work in to make a profit are crucial to the country's economy too. 


\section{ACCELERATION OF CANADIAN IMMIGRATION IN THE NATIONAL DEVELOPMENT OF KNOWLEDGE- ECONOMY}

\subsection{The Dominant Place of the Knowledge Economy in National Economic Development}

The knowledge economy is a new economic system that is as significant as the agricultural economy and the industrial economy. Thriving industries such as designing, engineering, information technology, marketing as so on are all included in this area. Based on the statistics on HRZONE, it has been estimated that more than $50 \%$ of GDP in major economic cooperation and development (OECD) countries is due to knowledge-based activities[9]. Different from the traditional form of economy, the knowledge economy has greater space and faster pace to make progress, as the academic area it relies on is changing considerably everyday, that is, the potential of the knowledge economy is infinite. Thus, it is clear that developing the knowledge economy plays a significant role in developing the national economy. In the global range, it is true that Canada has relatively strong competitiveness in the knowledge economy, as Global Innovation Index 2019, it ranks in 17th place.

Table 1: Canada's rankings of the Global Innovation Index (GII), 2017-2019

\begin{tabular}{cccc}
\hline Gal & $\begin{array}{c}\text { Innovation } \\
\text { Inputs }\end{array}$ & $\begin{array}{c}\text { Innovation } \\
\text { Outputs }\end{array}$ \\
\hline 2019 & 17 & 9 & 22 \\
\hline 2018 & 18 & 10 & 26 \\
\hline 2017 & 18 & 10 & 23 \\
\hline
\end{tabular}

For marketing sophistication, it is even in second place. However, this does not mean that the country does not need to take action to keep its place: countries such as China, the United States, Israel and Germany have similar innovation input/output performances (by income group) [10]. It is necessary for the country to think of a way to maintain its competitive advantages.

\subsection{The Contribution of Immigrants in the Canadian Knowledge Economy}

Even though the Canadian knowledge economy is thriving, skill shortage occurs in many fields of it. According to the report of TC Global, skilled workers like doctors, chartered accountants and software engineers, are highly demanded in recent years. "Hence there is a need for more methods that can capture both the demand for and supply of workers' skill," it said[11]. If the vacancy of those skilled positions remains for a relatively long time, it is very likely that the productivity of the knowledge economy area will be decent, the development of core technology in various fields will slow down, and the opportunities and space for knowledge exchange will be limited. In this era of the knowledge economy, Canada is likely to be left behind in many other countries. The disadvantages of a shortage of skilled workers cannot be ignored. For instance, in the single field of insurance, the lack of skilled workers can lead to various crises. According to Sovereign Insurance, the growth of a company can be influenced by this problem. Unfortunately, slower growth of a company is the flashpoint of a series of problems: more loosened standards in maintenance or quality control practice, the unsatisfying quality of work and so on[12]. If there are as many potential risks as possible in only one industry, the impact of the shortage of skilled talents on the whole society is self-evident. With the consideration of so many potential drawbacks of lacking skilled labour in the knowledge economy, seeking sources of them becomes an issue that is worth a discussion. On the basis of the official report of the Canada Government, many immigrants have excellent science, technology, engineering and math (STEM) skills, and they make up about half of all STEM degree holders in Canada. Therefore, attracting more immigrants to fill the vacancy in the knowledge economy is a necessary and wise choice. With the supplement of skilled immigrants, the Canadian knowledge economy will surely be accelerated.

\section{DISCUSSION}

Sean Simpson, vice-president of Ipsos Public Affairs, argues that there are common fears that some Canadians may hold about immigration, as immigrants are squeezing the size of the job market for domestic workers and causing a negative effect on the wages of domestic people."It might be the belief that people who are immigrating from other countries are a drain on the health-care system or the social assistance system. It may be that they're taking jobs from other people", he said[13].

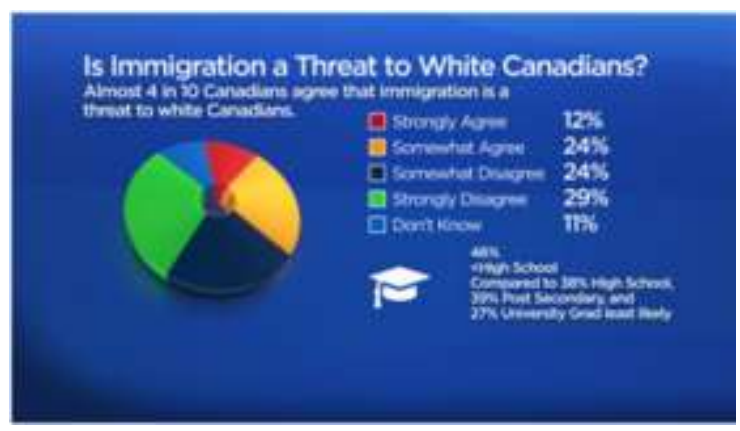

Figure 1: A survey conducted among Canadians on whether immigration poses a threat to white Canadians

Objectively speaking, however, this phenomenon has not been tested true in any study. For example, according to research done by Longhi, Nijkamp and Poot (2008) and reported in Duncan et al (2012), in 
most of the cases $(58 \%)$ immigrants implied hardly any negative effect on wages of domestic workers.[14] Furthermore, compared to the benefits that a majority working-age immigrant population can provide to the Canadian workforce, this problem seems too small to lead to a serious economic difficulty in Canada. Thus, accepting more immigrants should still be advocated.

\section{CONCLUSION}

In conclusion, immigration to Canada should be encouraged for the benefits of releasing burden on society because of the increasing aging population from the perspective of filling the vacancy of labour market to that of providing proper medical care to the increasing number of elder patients as well as giving the full play to the role of the knowledge economy in promoting the Canadian economy, guaranteeing the competitive status of Canada in the international society. Last but not least, worries about new immigrants competing for jobs are unnecessary. From a scientific perspective, the advantages of increasing immigrants to Canada always outweigh the drawbacks.

\section{ACKNOWLEDGMENT}

First, I would like to express my appreciation to my supervisors for their instructive suggestions and the kindest encouragement. If there is no their efforts, I would not manage to finish a paper on my own as a high school student.

Special thanks to my English teacher in my school who is willing to use his spare time to discuss basic skills of writing a paper. He has such an earnest attitude to tell me how to use proper diction in a paper.

I sincerely appreciate my friends who inspired me to write this paper about Canadian immigration. During the most difficult time, she was always by my side and was my warmest audience.

I am also grateful to my parents for their warmest care from China. Even though there is a $8,000 \mathrm{~km}$ distance between us, I can still feel their love to me.

\section{REFERENCES}

[1] Harold Troper. (2013) Immigration to Canada. https://www.thecanadianencyclopedia.ca/en/article/ immigration.

[2] Government of Canada (2020) \#immigrationMatters: Canada's immigration track record. https://www.canada.ca/en/immigration-refugeescitizenship/campaigns/immigration-matters/trackrecord.html\#health.

[3] PRB [Population Reference Bureau]. (2019) Countries With the Oldest Populations in the World. https://www.prb.org/resources/countrieswith-the-oldest-populations-in-the-world/.
[4] Gabriel Friedman. (2019) All the reasons why Canada needs immigration - and more of it. https://financialpost.com/news/economy/all-thereasons-why-canada-needs-immigration-and-moreof-it.

[5] Gordon, M. (2000) Problems pf am Aging Population in an Era of Technology. Journal of the Canadian Dental Association, 66: 320-2.

[6] Akbari, A.H. (1989) The Benefits of Immigrants to Canada: Evidence on Tax and Public Services. Canadian Public Policy/ Analyse de Politiques, 15: 424-435.

[7] Lucie Jeudy. (2021) Number of people immigrating to Canada in 2020, by age. https://www.statista.com/statistics/443305/internati onal-migrants-in-canada-2014/.

[8] Lahouaria Yssaad and Andrew Fields. (2018) The Canadian Immigrant Labour Market: Recent Trends from 2006 to 2017. https://www150.statcan.gc.ca/n1/pub/71-606-x/71606-x2018001-eng.htm.

[9] Conor Gilligan, (2019) The importance of the knowledge economy. https://www.hrzone.com/community/blogs/conorgilligan/the-importance-of-the-knowledge-economy.

[10] WIPO [World Intellectual Property Organization], (2019) Global Innovation Index 2019 -Canada. https://www.wipo.int/edocs/pubdocs/en/wipo_pub_ gii_2019/ca.pdf.

[11] TC Global. (2020) What are the skills Shortages in Canada?. https://helpcentre.tcglobal.com/hc/enus/articles/360036923651-What-are-the-skillsShortages-in-Canada-.

[12] Sovereign Insurance. (2020) The impact of the skilled labour

https://www.sovereigninsurance.ca/advice-andtools/hot-topics/the-impact-of-the-skilled-labourshortage.

[13] Maham Abedi. (2019) 37\% in Ipsos poll say immigration is a 'threat' to white Canadians what's the threat? https://globalnews.ca/news/5288135/immigrationthreat-canadians-poll/.

[14] Government of Canada. (2016) Economic and social objectives of immigration: The evidence that informs immigration levels and education mix. https://www.canada.ca/en/immigration-refugeescitizenship/corporate/reports-

statistics/research/economic-social-objectivesimmigration-evidence-that-informs-immigrationlevels-education.html\#effect. 